DEPARTMENT OF COMMERCE

\title{
Circular
}

OF THE

\section{BUREAU OF STANDARDS}

S. W. STRATION, DIRECTOR

No. 46

\section{THE TESTING OF BAROMETERS}

[2d Edition]

Issued July 15, 1914

WASHINGTON

GOVERINMENT PRINTING OFFICE 



\section{DEPARTMENT OF COMMERCE}

\section{Circular}

OF THE

\section{BUREAU OF STANDARDS}

S. W. STRATTON, DIRECTOR

No. 46

\section{THE TESTING OF BAROMETERS}

[2d Edition]

Issued July 15, 1914

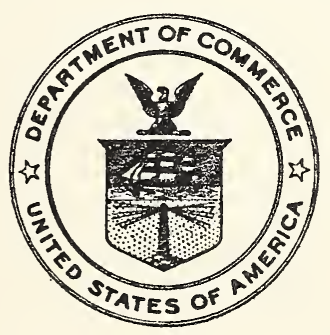

WASHINGTON

GOVERNMENT PRINTING OFTICE 



\section{THE TESTING OF BAROMETERS}

\section{CONTENTS}

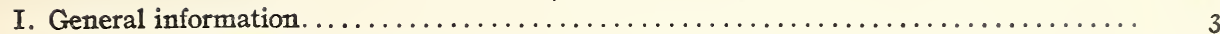

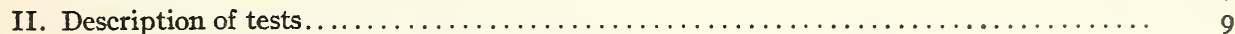

III. General instructions to applicants for tests. . . . . . . . . . . . . .

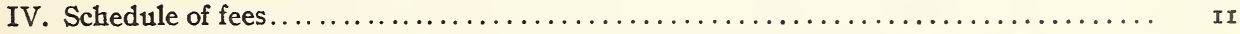

The present circular is of a preliminary character. It is issued in advance of the final results of the Bureau's investigations only in response to repeated requests for information. It will serve to describe in a general way the testing of mercurial and aneroid barometers at the Bureau of Standards, and to announce the fees which are charged for the various tests.

\section{GENERAL INFORMATION.}

In applying for a test of a barometer, whether of the mercurial or aneroid type, information as to the use to be made of the instrument should be furnished, since the degree of accuracy necessary in the test, and, in many cases, the choice of a suitable method of testing, depends upon this.

Mercurial barometers may be used in the form of primary standards with which other barometers are to be compared, or in the form of laboratory standards of high accuracy for determining the pressure of the atmosphere or the pressure in a closed system, in connection with the determination of steam points, the pressure coefficient of chemical reactions, etc. They may also be constructed in a moderately portable form to indicate altitudes in mountain explorations. Finally, they may be used, with somewhat less attention to the greatest attainable precision, for numerous meteorological and engineering purposes. The methods of testing mercurial barometers differ considerably according to the uses for which the barometers are intended. These differences of method depend chiefly on the standard which is to be used during the tests, on the necessary range of pressure and means of controlling the same, and on the total 
number of observations necessary to obtain a suitable degree of precision. The fees for testing mercurial borometers, therefore, vary considerably, as indicated in the fee schedules at the close of the circular.

Aneroid barometers are likewise used for a variety of purposes radically different one from another. The methods of testing aneroid barometers, however, do not differ greatly in experimental procedure, so that the fees charged for tests do not depend very much on the use to which the instrument is to be put. But the inferences to be drawn from an experimental test and the tolerances to be permitted in issuing certificates do vary according to this use.

Aneroid barometers may be used for weather observations, as on board ship; or for the determination of absolute altitudes, either with a slow rate of change of pressure as in mountain climbing, or with a rapid change of pressure as in aviation. They may also be used to determine relative altitudes, as in estimating the available water power of streams and of waterfalls. Finally, they may be used for interpolation between known altitudes not very far apart, as in establishing contour lines, and this is a most justifiable use of the aneroid barometer, provided suitable precautions are taken.

In order to contrast the requirements which are imposed upon the mechanism of an aneroid used for absolute measurements with those which are imposed upon the mechanism of an interpolation instrument, it is sufficient to call attention to the fact that for an absolute altitude determination in aviation the sensitiveness of the indications is of very small moment compared with freedom from elastic lag. On the other hand, for interpolation purposes freedom from elastic lag is a minor consideration, for as soon as reference has been made to the fixed altitudes between which the instrument is carried errors which are uniform cancel out, and the chief limitation in the usefulness of the instrument depends upon its freedom from mechanical irregularities.

Specifically, then, aviators' barographs ought not to receive a Bureau certificate if their indications depend very seriously on the speed at which the pressure is changed. A moderate degree of uncertainty in the action of the lever system is however permissible in view of the fact that the effect of this uncertainty will, in practice, be less than that of the vibrations of the machine, not to mention the inherent difficulties of barometric altitude determination. A surveying aneroid, on the other hand, ought not to receive a Bureau certificate unless the irregularities of mechanical action 
are extremely small, though a moderate degree of elastic lag is permissible so long as the instrument is used only for interpolation.

The precautions necessary in the use of barometers may be considered with reference to (I) the nature of the measurement in question, (2) possible defects in the barometer, (3) unavoidable sources of error in the instrument, and (4) the corrections which theoretically should be applied even though the instrument be mechanically perfect. While it is beyond the scope of this circular to present a detailed discussion, the character of these precautions may be briefly indicated in order to afford a basis for correspondence in regard to such matters on the part of applicants for test and others.

I. The importance of pressure control whenever exact pressure measurements are required in physical and chemical laboratory investigations is frequently not fully appreciated. Sometimes a considerable improvement in accuracy can be secured by eliminating minute fluctuations of air pressure simply by the use of a closed system of pressure connections in parallel with an air receiver of large capacity. There is, again, on the part of many who use either mercurial or aneroid barometers for altitude determination, a widespread tendency to regard the problem of barometric altitude determination in too optimistic a light. The theoretical difficulties involved are, in fact, serious. Aside from the obvious difficulties of proper allowance for the effect of temperature and humidity, not to mention the effect of wind and other local disturbances, it is not even correct in principle to employ the customary altitude scales or formulas in which the altitude is made proportional to the logarithm of the pressure, unless the temperature distribution throughout the vertical air column actually is constant from base to summit. For example, to take an extreme case in order more readily to illustrate the principle involved, if the temperature happened to vary directly as the pressure, in going up the air column, then the true relation between the altitude and pressure would be that the altitude varies inversely as the pressure and not at all in proportion to the logarithm.

2. Relative to the defects of barometers, it is easy to secure mercurial barometers quite free from defects, but it is difficult in the case of aneroid barometers unless a careful selection is made directly from the stock of a maker of high-grade instruments. Some of the defects in aneroid-barometers which have been encountered at the Bureau of Standards are the following:

Irregular graduation of the pressure scale. 
Altitude scale which can be revolved freely relative to the pressure scale, the altitude scale not being divided into equal parts.

The barometer case fitted with a mechanism properly belonging to a smaller sized instrument.

A piece of string included in the multiplying system in place of the usual metallic chain.

The adjusting screw in the base having so large a pitch that in attempting to adjust the position of the pointer the smallest possible movement of the screw driver moves the pointer over a large part of the scale.

Instrument engraved with the word "compensated" and yet not provided with any temperature-compensating device.

There are numerous other defects less frequently found or of less importance.

3. Barometers, like all other scientific instruments, are subject also to errors, as distinguished from defects. While defects can be avoided by inspection of the instrument, errors must exist qualitatively in all instruments, and can not be avoided in kind but merely minimized in degree.

The errors most commonly encountered in mercurial barometers are those due to capillarity, scale graduation and scale mounting, residual gas in the evacuated space, and apparent depression of the meniscus with increasing intensities of illumination.

The capillary depression of the mercury column in a barometer tube of I cm internal diameter is of the order of 0.2 to $0.4 \mathrm{~mm}$. It is greater the greater the meniscus height above the circle of contact between the mercury and the glass tube, and less the greater the bore of the tube. The capillary depression becomes excessive in tubes of very small bore, and in any given tube it is likely to vary from day to day as well as from point to point of the tube. It is consequently not customary to isolate the capillary error from the scale errors, although the net effect of capillarity and scale errors may conveniently be separated from the error due to residual gas. The gas error increases as the mercury approaches the top of the tube; consequently barometers should be adjusted to read with the mercury as far as possible below the top of the tube. The effect of increasing the intensity of illumination behind the sighting plates of a mercurial barometer of the usual type is to slightly lower the barometer reading. Within the limits of the inconstancy of the capillary error, the over-all instrumental correction of the mercurial barometer can usually be determined once for all and designated for practical use by a single numerical 
quantity unless the gas correction is a predominant factor, in which case the over-all correction can be expressed by an empirical calibration curve or the equation thereof. Such a correction need only be redetermined, as a precaution against the effects of rough handling.

With aneroid barometers, however, the case is different. Many of the errors here can not be represented by a single number but depend altogether upon the conditions under which the instrument is being used, and may, indeed, undergo secular changes. It is, however, a mistake to accept literally the popular impression that the aneroid barometer is entirely erratic and undependable. The facts are that the errors of aneroid barometers are numerous, large, and variable; but they are not indefinitely numerous, and their magnitude can be approximately determined in each case. The variation of any given error, while perplexing to a person obliged to use the instrument, appears to follow definite physical laws. While, then, it is true, that the errors of an aneroid barometer can not be so well corrected for as those of a mercurial barometer, they can be corrected for to a greater or less degree, depending on how much time it is worth while to devote to testing and correcting the instrument, and providing of course that to begin with, the aneroid is free from defects.

The errors of aneroid barometers may be classified under four heads, namely, mechanical errors, thermal errors, elastic errors, and secular errors. The chief mechanical errors are those due to the necessity for a compromise between friction and back lash in the link work, and those due to the difficulty of securing perfect balance among the movable parts. Precautions to minimize the effect of mechanical errors are, first, to read the aneroid always in the same position, preferably the horizontal position, unless the aneroid is obviously made to be hung up; and second, to tap the instrument sharply just before reading.

Thermal errors are due to the expansion of the parts under varying temperature, and to avoid them the instrument should be tested under as great a range of temperature as will be encountered in practice. Some aneroids which are well compensated at ordinary temperatures show very inadequate compensation at extreme temperatures, although it is possible to purchase aneroids which are successfully compensated over a range of $100^{\circ} \mathrm{F}$.

Elastic errors in aneroids, usually designated by the single term "elastic lag," are evidenced first, by the tendency of an aneroid to "drift" in its readings when held for several hours at a constant low pressure; 
second, by the fact that the reading at any given pressure depends on the previous rate of change of pressure; and, third, by the discrepancy between the readings of an aneroid at a given pressure according as the pressure has been falling or rising. The existence of the first of these effects necessarily leads to that of the other two. Whether there exists a type of hysteresis due to reversal of action independently of time or not, it is certain that the predominating errors are those due to drift. Consequently, the most important precaution to take in order to avoid the effect of elastic errors is to ascertain in advance, and most conveniently by the regular Bureau test, the maximum drift which can take place in a given number of hours. In fact it is possible to correct, roughly, for the effect of elastic errors when the exact circumstances under which the instrument was employed-particularly as regards the rate of change of pressure-are known.

While true secular errors may exist due to the gradual settling of the parts, or other causes, these need not be of serious concern if the instrument is checked up from time to time with a mercurial barometer. Beside the true secular changes there are rather sudden changes which would on first thought be supposed to be secular changes, but which are either shown by close observation to be sufficiently explicable in terms of elastic lag resulting from the daily fluctuations of the atmosphere, or which may be ascribed to some actual injury of the instrument.

4. Relative to the theoretical corrections which are to be applied to barometers, assuming the instruments themselves to be perfect and provided the barometer is regarded purely as an instrument for determining pressure, no corrections at all need be applied to the aneroid barometer, while the mercurial barometer reading must be reduced to what it would have been if the force of gravity had a certain standard value and if the mercury and the scale had been at certain standard temperatures. Complete corrections to the mercurial barometer for temperature and gravity are to be found in the Smithsonian Physical Tables and elsewhere. Strictly speaking, the barometer measures pressure only, any fixed relation between pressure and altitude being impossible. Practically, however, such relations can be formulated which will be roughly fulfilled by assuming for the air column a particular mean humidity, a particular mean temperature, and perfectly static conditions. Such a relation is afforded by the table of Prof. Airy, published in the Proceedings of the British Meteorological Society of April, I 867, pages 406 to 407 , which is the table in common use for graduating the scales of aneroid barometers in English units. 


\section{DESCRIPTION OF TESTS}

The gas correction of primary standard mercurial barometers is determined at the Bureau by forcing the mercury nearly to the top of the tube while comparing from point to point the indications of the barometer with those of an auxiliary barometer. During the comparison of mercurial barometers attention is given to the elimination of temperature gradients along the tube as well as temperature lag.

For laboratory standards, which are secondary instruments, the gas correction is not isolated from the other corrections, but an over-all calibration correction is obtained by comparison with another barometer connected up into the same pressure-tight system while the pressure is varied over the desired range. In tests of the highest precision reference is made directly to a primary standard barometer, but in the majority of tests the use of a previously standardized secondary barometer is sufficient. Frequently the use to which laboratory standards are to be put does not demand a complete calibration curve and a simple test at the atmospheric pressure is sufficient. Marine or compensated-scale barometers giving no indication of the position of the mercury in the cistern should, however, always be calibrated over a wide range of pressure.

High-altitude mercurial barometers are tested in a similar way except that even for testing at a single point it is necessary to control the pressure artificially in order that the mercury may stand at the desired height. Simply testing at one point will not serve to detect the existence of air in the evacuated space and consequently a correction so furnished is valid only in the immediate neighborhood of one particular pressure.

For commercial barometers of a lower grade such as may be used for computing the condenser pressure in steam-engine tests in conjunction with the reading of a differential gage, or for determining the range corrections in coast artillery practice, or for many meteorological purposes, the tests are, in principle, carried out in the same manner as described above. They are executed more quickly, however, and in view of the small internal diameter of the tubes employed in this lower grade of barometer, observations to so high a degree of precision as before would be superfluous.

The testing of aneroid barometers consists primarily in comparing the aneroid from point to point with a standardized mercurial barometer both with decreasing and increasing pressure, the pressure being changed at approximately the rate of $I$ inch in five minutes. On reaching the lowest point of the scale the pressure is held constant for five hours. 
From these observations an approximate calculation can be made of the corrections which ought to be applied to the aneroid in practical use if the pressure were to be changed at such a rate that any given point for which the correction is to be deduced would be reached 24 hours after the start. The discrepancy between these "fast" and "slow" corrections may then be taken as a measure of the reliability of the aneroid so far as affected by drift, while the particular correction which ought actually to be used when the pressure is decreased at an intermediate rate must lie somewhere between the two. In addition to this test, aneroids are regularly put through a simple examination to show the precision with which they are capable of being read at any one point of the scale, so far as this may be influenced by friction, back lash, or lack of balance in the mechanical parts.

Finally, the temperature coefficient will be determined if requested and, where the aneroid has been used for exploration or other work of importance, special tests at specified rates of change of pressure, to duplicate service conditions, will also be made if requested.

\section{GENERAL INSTRUCTIONS TO APPLICANTS FOR TESTS}

(a) Application for Test.-All articles submitted for test should be accompanied by a written request. This request should enumerate the articles, giving the identification marks of each, and should state explicitly the nature of the test desired as well as the use to which the instrument is to be put. It is suggested that a prior application be made from two weeks to a month preceding the shipment of the apparatus if it is desired that the test be made promptly when the apparatus is received, inasmuch as regular tests are made in the order in which the applications are received, except as this practice may be varied by grouping similar tests together. This will facilitate the work of the Bureau as well as the prompt return of the apparatus. When the test is one regularly provided for in the appended schedules the fee may be computed in advance and should be sent at the time the apparatus is shipped.

(b) Shipping directions.-Apparatus should be securely packed in cases or packages which will not be broken in transportation and which may be used in returning it to the owner. Transportation charges in both directions are payable by the party requesting the test and transportation is at his risk. All packages should be plainly marked with the shipper's name and address and, when convenient, with a list of the contents. Each separate piece of apparatus should be provided with an identification mark or number. 
(c) Address.-Apparatus submitted for test, as well as all correspondence, should be addressed simply "Bureau of Standards, Washington, D. C."

(d) Remittances.-Fees in accordance with the following schedule should be sent when the apparatus is shipped, or promptly upon receipt of bill. Certificates are not given, nor is apparatus returned, until the fees due thereon have been received. Remittances may be made by money order or by check drawn to the order of the "Bureau of Standards."

\section{SCHEDULE OF FEES}

\section{SCHEDULE 110.--Mercurial Barometers}

\section{Class I}

(Primary Standard Barometers)

(a) Gas correction and investigation of capillary errors. Fees determined after correspondence.

Class II

(Laboratory Standards with Bore Greater than $1 \mathrm{~cm}$ )

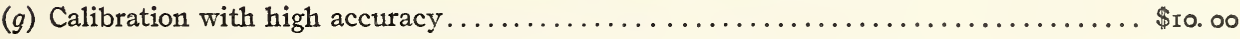

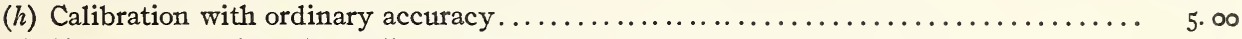

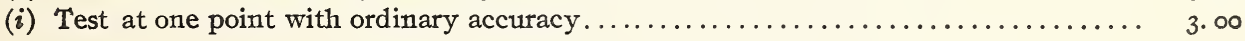

\section{Class III}

(High Altitude Barometers with Bore Less than $1 \mathrm{~cm}$ )

$(m)$ Calibration with ordinary accuracy................................... \$1 .

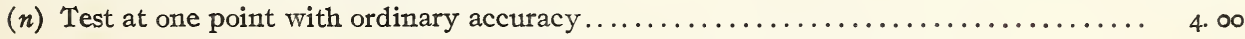

Class IV

(Common Barometers, Bore Less than $1 \mathrm{~cm}$ )

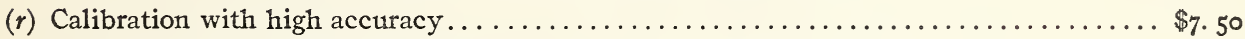

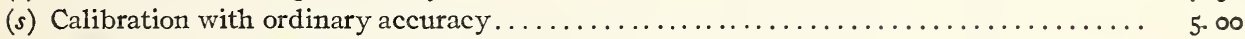

( $t$ ) Test at one point with ordinary accuracy..................................

\section{SCHEDULE 111.--Other Mercury Gages}

(Fees determined after correspondence.)

\section{SCHEDULE 112.-Aneroid Barometers}

(a) Regular test, ordinary accuracy. Fee 50 cents per inch range of pressure below the 30inch point independently of the number of instruments tested, plus $\$ 1.00$ for each individual aneroid.

(b) Temperature coefficient, $\$ 2.50$ for one plus $\$ 1.00$ for each additional aneroid submitted.

(c) Test at any specified rate of change of pressure. Fees determined after correspondence.

(d) Short test, giving approximate correction at lowest point of scale to insure that aneroid is in good working order, but not recommended where an accuracy better than 3 per cent of range is desired. 
For the testing of barometers to an exceptional degree of accuracy, or for calibration over an exceptional range of pressure, a further charge will be made. For testing the scales or thermometers attached to barometers the fees will be in accordance with Circulars Nos. 2 and 8, respectively.

For educational and scientific institutions and societies a discount of 50 per cent will be allowed on all tests under the above schedules. Government or State authorities entitled to tests free of charge under the law must make application in writing for each test in order to avail themselves of the privilege.

S. W. Stratton,

Director.

Approved:

WILLIAM C. REDFIELD, Secretary. 